\title{
The Relationship among Personality and Beliefs about Knowledge on Study Approach : Evidence from Top Indonesian Universities Accounting Students
}

\author{
Alfiati Silfi $^{\mathrm{a}}$, Mohammad Ali Abdul Hamid ${ }^{\mathrm{b}}$ \\ Department of Accounting, Faculty of Economics, University of Riau ${ }^{a}$ \\ School of Accountancy Northern University of Malaysia ${ }^{b}$ \\ alfiatisilfi@gmail.com ${ }^{\text {a }}$, malizai25@gmail.com ${ }^{\text {b }}$
}

\begin{abstract}
The objective of the study is to investigate the relationship between personality factors and beliefs about knowledge on study approach among on accounting student in Indonesian top universities. Personality factors consists of five dimensions of personality known as The Big Five Personality and Beliefs about knowledge consists of four dimensions, known as epistemological beliefs, whereas study approach consists of three parts: a deep study approach, surface study approach and strategicstudy approach.The sample in this study is from 250 accounting students at several top universities in Indonesia. Data were analyzed with SEM by using LISREL to examine the relationship among the variables.The result shows that personality and beliefs about knowledge influence the approach directly.Furthermore, personality factors didnot influence the study approach indirectly through their effect on beliefs about knowledge.
\end{abstract}

Keywords: Personality,beliefs about knowledge, Study approach, deep study approach, surface study approach, strategic study approach.

\section{INTRODUCTION}

Beginning in 2012, Indonesia began to adopt in full the international financial report standards (IFRS). The emergence of IFRS could not be separated from global developments, especially those that took place in the capital markets. The development of information technology in a market environment which happened so fast by itself have an impact on aspects of the capital market. Development of a globalizing world in itself demands an accounting standards required both by capital markets or institutions that have agency problems..

To generate information about the State of a company that can meet the needs of various parties made the profession of Accountants increasingly play an important role. Accountants play an important role in all aspects of business activity. The Accountant responsible for the process control and design of making accurate financial information of a company, being a consultant for business development, finance and others. The job of an accountant is not only limited to the preparation and reporting of financial and business information, but also plays a role in providing assistance for internal company in the process of planning, control and decision making.

The important question for today is how is the readiness of the profession accountant in Indonesia in providing qualified and competent skills in the field of accounting? How about the readiness of the accounting education in the world bear the accountants qualified and competent? In 1989 The Big accounting firms (Davidson,2001) States that a public accountant graduated into is not a goal but the most important is how the profession as an accountant has the ability in analyzing and conceptual thinking in the face of the challenges and opportunities for a company.

Development of the ability to analyze and think conceptually require a learning process that's very different than just have the capability as simple as memorizing that rely solely on the ability of remembering and structured (Svensson, 1977). The ability to achieve the accounting education must be organized and managed to produce an accountant who has the ability to analyze well one diverse issues from a structured until the conditions are complicated and unstructured.

Development of the ability to analyze and think conceptually require a learning process that's very different than just have the capability as simple as memorizing that rely solely on the ability of remembering and structured (Svensson, 1977). The ability to achieve the accounting education must be organized and managed to produce an accountant who has the ability to analyze well one diverse issues from a structured until the conditions are complicated and unstructured.

Different learning strategies may serve as the mechanism for obtaining the required knowledge in a rapidly changing environment. Consequently, students who adopt the most appropriate learning strategy in a particular context are likely to be more successful than less skilled learners (Entwistle, 1998). The purpose of this study to provide empirical evidence on the relationship among personality factors and beliefs about knowledge on Study approach. While the research questions in this research is : 
1. Do Personality factors influence on the study approach directly?

2. Do Personality factors affect the beliefs about knowledge ?

3. Do Beliefs about knowledge impact study approach ?

4. Do Personality factors influence indirectly on the study approach and mediated by Beliefs about knowledge?

\section{LITERATURE REVIEW}

\section{Students'Study Approachs}

Study approach is a method of learning that focuses on the quality of learning. According to some researchers stated that education to improve the quality of learning is very important to understand the learning approach of protege. The learning approach that used college students is a very important factor to improve the quality of learning and their academic success. Research on student learning in the University system could be useful for improving the system of learning and teaching (Zeegers, 2001). Motivate students to improve the learning approaches can improve the quality of learning. Approaches to learning are a source of understanding of learning and teaching and is very useful for educators to understand the ways of learning and student body to create a learning environment that can help them get the desired results. How students use learning approach will be very strongly affect the quality of their learning results. Duff (2004) formulated that benefit educators need to measure student learning approaches:

1. To establish a system of academic learning approach.

2. To help the individual academic focus to monitor and improve the effectiveness of their learning.

3. To identify the risk through the ineffectiveness of learning strategies.

4. For observing the results and learning experience.

5. For evaluating the quality of learning.

The dimensions of the Study Approach: (Hasnor,2012)

1. Surface study approach, the dimension : Lack of purpose, Unrelated memorizing,Syllabus boundess, and fear of failure.

2. Deep Study approach, the dimension : Seeking meaning, relating Ideas, use of evidence and interest in ideas.

3. Strategic study approach,the dimension: Organised studying, time management, alertness to assessment studying.

Ramsden (1992) stated that the results of student learning can be influenced directly from the focus of attention with respect to learning.The learning approach that they use in learning can be beneficial to focus learning and also their perceptions of tasks carried out. The perception of the task of learning can be affected by learning methods such as curriculum, teaching and assessment methods (Duff et al,2004).

\section{Personality Factors}

Personality is a variable that is widely used in behavioral studies in various fields of science. According to Graziano (2003) argument about the structure of the personality or no less and less since 20 years ago. For accounting research field, this variable was not yet widely used. However some researchers such as Roberts, Caspi and Moffit argues that personality variable has expired since 1995. While Costa and McCrae argue that personality is stable its use over the past 30 years $(1986,2000)$. Elsewhere, Lewis (1988) States the development of personality over the span of life.

Dimensions of personality that are popular to use in the field of research is known as the big five personality dimensions, namely:

1. Neuroticsm

Neuroticsm is the personality values containing the meaning of stiff, unstable emotions, lack of responsibility and not reliable.(Hogan et al,1994).Neoroticsm also includes a set of properties of the confused, depressed, and fragile (Piedmont, 1998).

2. Openness

Openness is the personality values containing the meaning of the individual's ability to imagine, broad-minded and all want to know. (Hogan et al,1994). Openness involves a set of properties of a person who likes to imagine, like going to art and beauty, full of feeling, have a lot of ideas (Piedmont,1998).

3. Agreeableness

Agreeableness are personality values containing the meaning of one's sympathy, cooperative, and friendly.(Hogan et. Al,1994). While according to Piedmont (1998) what is meant by agreeableness is trustworthy nature, likes to come clean, polite and tend to like to think.

4. Conscientiousness

Conscientiousness are personality values containing the meaning individuals who like to work hard, love to perform duties, controlled (DeNave et al,1998). While according to Hogan et al (1994) is competent, diligent on duty, self-discipline, full consideration. Furthermore conscientiousness include competence, a strong desire to achieve a certain target, full of discipline and full consideration (Piedmont,1998).

5. Extraversion

Extraversion is personality values containing the meaning of gregarious, assertive, positive emotions, sometimes Extraversion may also refer to energetically (Piedmont,1998). In addition Extraversion focuses on the quality and intensity of the relationship either (Deneve et al,1998).

Someone who has the personality factors that tend to use sophisticated approach to learning that deep 
approach te also sophisticated and rather naïve personality can be related to learning methods such as surface which is easy to approach. Duff et.al study (2004) that examines the relationship between personality, approach to learning and academic performance indicates that the personality factors such as extraversion and openness related positively to deep approach, and neuroticsm and agreeableness are associated positively with surface approach, as well as extraversion and conscientiousness is positively related to the strategic approach, instead dealing with the negative neuroticsm. Duff research results (2004) this is consistent with previous studies (Busto et al 1999,2000 and De Raad \& Schounwenburg 1996).

Beliefs About Knowledge (Beliefs dimension)

Research on epistemological beliefs evolved and become complex for psychology and for educators. Schommer (1990.1993) identified several limiting beliefs about knowledge that is essential for the success of students in the future. In the field of accounting, Friedlan (1995) found that beliefs are based on the approach of different teaching methods in cases with that are based beliefs about knowledge only upon giving lecturer. Schommer (1990) has divided the beliefs of knowledge and learning in four dimensions, namely:

1. Certain (undeniable)

This first dimension indicated that naïve students would believe that knowledge was uncertain and undeniable, on the other hand other students believe about more sophisticated view that knowledge was uncertain and flexible.

2. Simple

The second dimension reflected students beliefs that varied about whether or not knowledge consisted of complex groups from an easy element integration or fact classification.

3. Could be obtained quickly

The third dimension included naïve students who viewed learning as could be obtained quickly and also other students with more sophisticated views, who believed that learning needed hard works.

4. Without any Limit

The fourth dimension showed that several students who have a naïve perpectives viewed that knowledge came after talent and on the other hand there were more sophisticated views with the belief of knowledge that can be added everytime.

Philips (1998) examined the relationship between beliefs about about knowledge on performance test results showed that the sophisticated beliefs affect the performance of a complex examination and does not affect the performance of a simple test. And Davidson (2002) research that examined a study on the influence of aapproach of exam performance shows that deep study approach to exam performance is complex and deep study approach not related to exam performance that is simple, in addition the use of surface study approach has no effect on exam performance. Then the research results a Cano (2005) examine the relationship between epistemological beliefs on academic performance that is mediated by the approach to learning showed results that epistemological beliefs directly impact academic achievement and indirectly through learning approach..

\section{RESEARCH METHOD PARTICIPANTS}

The participants were 250 accounting students from top universities in Indonesia.The University, which provided the population are some of the public and private universities in several cities and provincial capitals in Indonesia. As for the University become the sample in this research is a public and private university which is at some level A accreditation, which is determined by the national accreditation Agency (BAN) by 2015. The number of the University consists of 5 universities are respectively composed of 50 students in accounting. The following is a list of the names of universities that serve these samples: University of Indonesia, University of Padjajaran, Muhammadiyah University of Yogyakarta, Diponegoro University and Brawijaya University. IV.INSTRUMENT OF THE RESEARCH

The instrument of Study approach using questionnaire developed by Biggs (1987). The questionnaire began with a likert scale using five starts from 5 (strongly agree), 4 (agree), 3 (neutral), 2 (disagree) and 1 (strongly disagree). Personality Factors questionnaire is an instrument known as The Big Five Personality developed by Costa and Robert (1995), known as NEO-PI-r. All of the above instruments consists of five likert scale which starts from 5 (strongly agree), 4 (agree), 3 (neutral), 2 (disagree) and 1 (not very stuju). Limiting Beliefs are the instruments the questionnaire developed by Schommer (1990,1993). This questionnaire began using likert scale of five darng that starts from 5 (strongly agree), 4 (agree), 3 (neutral), 2 (disagree) and 1 (strongly disagree).

\section{DATA ANALYSIS TECHNIQUES}

Data that has been collected is analyzed with the correlation and regression analysis tool with use Structural Equation Models (LISREL) is analyzed with the correlation and regression analysis tool with the help of Structural Equation Models (LISREL). Results of the analysis will consist of testing the quality of the data, test assumptions of classical, regression analysis and test hypotheses. Data that has been collected is analyzed with the correlation and regression analysis tool with use Structural Equation Models (Lisrel Programme).

\section{VI.RESULT AND DISCUSSION}

Structural equation models of Accuracy (Structural Equation Modelling (SEM)) obtained are indicated by the size of the conformance model (Goodness of fit measures) (Hair, 2006, 640). The 
overall model test results meet the size of the conformance model (Goodness of Fit). Thus it can be said a good model (acceptable) to explain the relationships and the influence of Beliefs About Knowledge and Personality Factors on the Study Approach.

\section{VII.THE RESULTS OF STRUCTURAL MODEL}

Influence of structural model of Personality acquired Factors of limiting Beliefs About Knowledge are as follows:

Beliefs $=0.5647 *$ Personai, Errorvar. $=0.6811, \mathrm{R}^{2}=$ 0.3189

and the influence of Personality Factors and Beliefs About Knowledge of the Study Approach is as follows:

StudyApp $=0.5227 *$ Beliefs $+0.5294 *$ Personai, Errorvar. $=0.1340, \mathrm{R}^{2}=0.8660$

$(0.2246) \quad(0.2441)$
2.3266

$2.3266 \quad 2.1688$

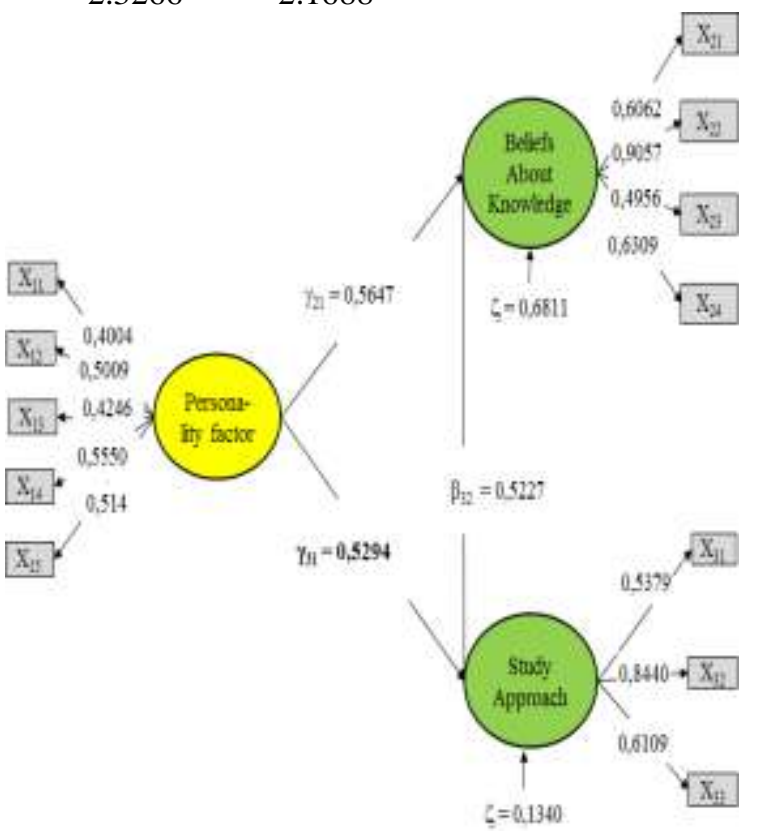

Figure 1

\section{Structural Model}

Based on the results of the calculation obtained value for $t$ calculate Personality Factors of 4,4508. the value of the test statistic t obtained is in the reject $\mathrm{H} 0$ i.e. $\mathrm{t}$ statistic is greater than 1.96. ( $\mathrm{t}$ statistic $4,4508>1.96$ ) then it can be taken a decision to reject H0. So inconclusive test results statistics show that Personality Factors affect the Beliefs About Knowledge.The magnitude of the influence of Personality Factors of limiting Beliefs About Knowledge is $(0,5647 \times 0,5647 \times 100 \%)=31,89 \%$.
So Personality Factors exert influence directly of 31,89\% against Beliefs About Knowledge.

Based on the results of the calculation obtained value for $t$ calculate Personality Factors of 2,1688 . the value of the test statistic t obtained is in the reject $\mathrm{H} 0$ i.e. $\mathrm{t}$ statistic is greater than 1.96. (t statistic $2,1688>1.96$ ) then it can be taken a decision to reject H0. So inconclusive test results statistics show that Personality Factors influence on the Study Approach. The magnitude of the influence of Personality Factors on the Study Approach is $(0,5294 \times 0,5294 \times 100 \%)=$ $28.03 \%$. So Personality Factors exert influence directly of $28.03 \%$ of Study Approach.

Based on the results of the calculation obtained value for $t$ calculate Beliefs About Knowledge of test statistic Values 4,302. $\mathrm{t}$ obtained is in the reject $\mathrm{HO}$ i.e. $\mathrm{t}$ statistic is greater than 1.96. $(\mathrm{t}$ statistic 4,302 > 1.96) then it can be taken a decision to reject $\mathrm{H} 0$. So inconclusive test results statistics showed that Beliefs About Knowledge impact Study Approach. The magnitude of the influence of Beliefs About Knowledge of the Study Approach is $(0,5227 \times$ $0,5227 \times 100 \%)=27,32 \%$. So limiting Beliefs About Knowledge provide the influence directly of $27,32 \%$ against Study Approach.

Personality Factors hypothesized to affect Study Approach mediated by Beliefs about knowledge. The path Coefficients obtained Personality of Beliefs about knowledge $\left(\gamma_{\times 2 \times 1}\right) \quad 0,5647$ and the coefficient of the Beliefs about knowledge of the Study approach gained $\left(\gamma_{\times 3 \times 2}\right)$ of 0,5227 . So can the influence of Personality on the Study approach through limiting Beliefs about knowledge is $0,5647 \times 0,5227 \times 100 \%=$ $29,52 \%$.

Testing this hypothesis to test the influence of indirect Personality to Study approach that mediated by Beliefs about knowledge. The value $t$ statistic 1,3336 is smaller than 1.96 which means that parameters of the mediation is not significant. It is thus not directly influence model of Personality to Study approach that mediated by Beliefs about knowledge not accepted (not significant). So Personality has no effect on the Study approach through limiting Beliefs about knowledge

\section{SUMMARY AND CONCLUSION}

This research aims to test the influence of Personality on Beliefs about Knowledge as well as the direct influence of personality on the Study approach and not directly with mediated by Beliefs about knowledge. The results showed that there were direct of influence between the Personality on Beliefs about knowledge and there is a direct influence of Personality on the Study approach, but the results showed that Beliefs about knowledge did not mediate the relationship between personality proved to study approach. Limitations of this research only using data on student accounting at top university level, the highest possible results can be different when also 
using data on universities in the middle and lower levels. For future research are advised to look for variable that can mediate the relationship between personality of the study approach, especially in the field of accounting.

\section{REFERENCES}

Biggs,J.B. (1987). Study process questionnaire manual. Vic: Australian Council For Educational Research.

Busato, V. V., Prins, F. J., Elshout, J. J., \& Hamaker, C. (2000). Intellectual ability, learning style, personality, achievement motivation and academic success of psychology students in higher education. Personality and Individual Differences, 29, 1057-1068.

Busato, V. V., Prins, F. J., Elshout, J. J., \& Hamaker, C. (1999). The relation between learning styles, the Big Five personality traits and achievement motivation in higher education. Personality and Individual Differences, 26, 129-140.

Cano Fransisco.(2005). Epistemological Beliefs and Approaches to learning : Their change through secondary school and their influence on academic performance. British Journal of Educational Psychology,75,203-221.

Costa, P.T.Jr. and McRae,R.R.(1992). Four ways five factors are basic. Personality and Individual Differences.

Costa, P.T.Jr. and McRae,R.R.(1995). Domains and Facets : hierarchical personality assessment using the revised NEO personality inventory. J.Pers.Assess, 64,21-50.

Davidson, R. A.(2002). Relationship of Study Approach and Exam Performance.Journal of Accounting Education.

Deneve,K.M. and Cooper H.(1998). The Happy Personality : A Meta analysis of 137 personality traits and subjective well-being. Psychological Bulletin., 124,197-229.

De Read B and Schounwenburg, H. C. (1996). Personality traits in learning paradigm ultility in business and management education. Paper presented at the Academy of management conference, Washington,DC,August 2001.
Duff Angus, et a.l (2003). Quality of learning on an MBA programme: the impact of approaches to learning on academic performance.Educational Psychology.

Duff Angus, et al. (2004).The Relationship between Personality, Approach to learning and Academic Performance. Personality and Individual Differences,36,1907-1920.

Entwistle,N. (1998). Approaches to learning and forms of understanding, In B. Dart and Bolton Lewis (Eds), Teaching and learning education (pp.79-85), Melbourne : ACER Press.

Friedlan, J. M. (1995). The Effect of Different Teaching Approaches on Students' Perceptions of the Skills Needed for Success in Accounting Courses and by Practicing Accountants. Issues in Accounting Education.

Graziano, W.G(2003). Personality Development : An introduction toward process approaches to long-term stability and change in person. Journal of Personality, 71,893-903.

Hasnor Hanim Naiha et al.(2013). The relationship between learning approaches and academic achievement among Intec Students UITM Shah alam. Social and Behavioral Science 90,178-186.

Hogan, R., Curphy, G,J., and Hogan,J.(1994).What We Know About Leadership : Effectiveness and Personality.American Psychologist.49, 493504.

Lewis, M.(1998). Altering Fate : Why the past not predict the future. Psychological Inquiry, 9,105-108

Piedmont, R.L.,(1998). The revised Neo Personality Inventory Clinical and reserach applications. New York :Plenum Press.

Phillips Fred.(1998). Accounting students'associating beliefs about knowledge : Associating Performance with Underlying Belief Dimensions .Issues In Accounting Education.

Ramsden, P. (1992). Learning to teach in higher education . London : Routledge.

Roberts,B.W., Caspi,A.,and Moffit,T.E.(2001) The kids are alright : Growth and Stability in personality development from adolescence to adulthood. Journal of Personality and Social Psychology,81,670-683. 
Schommer M.(1990) Effects of beliefs about the nature of knowledge on comprehension. Journal of Educational Psychology,82,498-504.

Schommer M (1993). Epistemological development and academic performance among secondary students, Journal of Educational Psychology,85,406-411. .

Svensson L.1977. On a qualitative differences in learning:III Study skill and learning. British Journal of Educational Psychology,47.233-243.

Zeegers, P. (2000). Approaches to learning in Science : a longitudinal study. British Journal of educational psychology,71,115-132. 